\title{
Preparation and Application of Sewage Sludge Bio- char/zero Valent Iron (SSBC/ZVI) Composite for Improving the Biodegradability of a Real Chemical Synthesis-based Pharmaceutical Wastewater
}

\section{Gaoxiang Qi ( $\nabla$ qigx@ctbu.edu.cn )}

Chongqing Technology and Business University https://orcid.org/0000-0003-3175-6647

\section{Xiaobo Wang}

Chongqing Technology and Business University

Xuecheng Liu

Chongqing Technology and Business University

\section{Shen Yu}

Chongqing Technology and Business University

\section{Research Article}

Keywords: Pharmaceutical wastewater, Micro-electrolysis, Sewage sludge biochar, Advanced oxidation processes, Biodegradation index, Wastewater pretreatment

Posted Date: May 25th, 2021

DOI: https://doi.org/10.21203/rs.3.rs-483449/v1

License: (c) (1) This work is licensed under a Creative Commons Attribution 4.0 International License. Read Full License

Version of Record: A version of this preprint was published at Waste and Biomass Valorization on September 20th, 2021. See the published version at https://doi.org/10.1007/s12649-021-01574-z. 


\section{Abstract}

A new kind of micro-electrolysis filler sewage sludge biochar/zero violent iron (SSBC/ZVI) composite was prepared for a real chemical synthesis based pharmaceutical wastewater (CSPW) pretreatment for improving the biodegradation index $(\mathrm{BI})$. The optimal operation condition of micro-electrolysis system was obtained at HRT of $2 \mathrm{~h}$, the initial pH of 3.0 and filler dosage of $100 \mathrm{~g} / \mathrm{L}$, with COD removal rate of $30.5 \%$. Comparative analysis of raw and used SSBC/ZVI filler, GC-MS analysis of raw and treated pharmaceutical wastewater suggested that the pollutants removal was mainly attributed to the combination of reduction and oxidation, absorption of SSBC and flocculation effect of iron sludge. In addition, SSBC/ZVI exhibited relative high stability and excellent reusability for COD removal and $\mathrm{BI}$ improvement of real pharmaceutical wastewater. The results of this study provide new ideas of sewage sludge utilization for real wastewater pretreatment.

\section{Introduction}

The pharmaceutical industry is one of the most polluting industries which generating huge amount of wastewater during the production process. The composition of wastewater produced from different pharmaceutical units differs obviously, and the organic content in chemical synthesis based pharmaceutical wastewater (CSPW) usually varies between 800 and 29,000 mg/L [1]. Moreover, pharmaceutical wastewater (PW) containing hazardous and recalcitrant compounds are often nonbiodegradable [2, 3]. PW treatment is a very challenging task because of its varying composition, recalcitrant nature, high toxicity, and low biodegradability [4]. Various techniques have been developed for PW treatment including physicochemical methods such as adsorption, sedimentation, advanced oxidation processes (AOPs) and biochemical methods [5,6]. Although biochemical processes provide the cheapest option for wastewater treatment, it often exhibits limited pollutants removal efficiency for PW with high toxicity. AOPs provide an efficient option to treat effluents with low biodegradability. Therefore, varieties kinds of AOPs techniques were explored to remove the refractory pollutants and to improve the biodegradability index (BI, BOD5/COD) of PW [7].

Micro-electrolysis technique attracted much more attention recently in refractory wastewater pretreatment due to its low operation cost, simple process control and high pollutants removal efficiency [8]. Fe-C micro-electrolysis has been proven to be highly efficient and low-cost in the treatment of various wastewater, including pharmaceutical wastewater [9], petroleum wastewater [10], chemical wastewater [11], etc. In Fe-C micro-electrolysis system, $\mathrm{Fe}^{0}$ and activated carbon (AC) act as the anode and cathode, respectively, and numerous microscopic galvanic cells will form spontaneously. In anode, $\mathrm{Fe}^{0}$ loses electrons and dissolves into the solution in the form of $\mathrm{Fe}^{2+}$. For the cathode, $\mathrm{AC}$ accepts and transfers the electrons to the acceptors. Under anoxic conditions, $\mathrm{H}^{+}$will accept the electrons to form $[\mathrm{H}]$ with

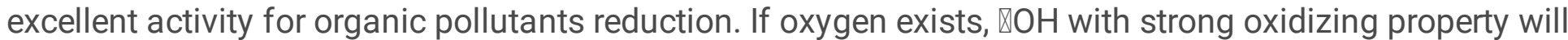
form and the organic pollutants will be oxidized. [12]. In addition, the pollutants removal by Fe-C microelectrolysis also includes the adsorption of $\mathrm{AC}$ and the flocculation and precipitation effect by ferric and 
ferrous hydroxides. The pollutants removal mechanisms by micro-electrolysis pretreatment can be summarized as oxidation reduction, coagulation and flocculation, physical adsorption [13]. Previous studies suggested that high COD removal efficiency can be achieved by micro-electrolysis pretreatment and the $\mathrm{BI}$ values of refractory wastewater with high organics concentration can be improved obviously [5].

Sewage sludge bio-char (SSBC) is one of the pyrolysis products of sewage sludge, which can be used as an adsorbent for wastewater treatment. In this study, a new kind of micro-electrolysis filler SSBC/ZVI composite was prepared using SSBC as the cathode for pretreating a real chemical synthesis-based pharmaceutical wastewater. Micro-electrolytic fillers preparation using SSBC for PW pretreatment process is expected to realize the waste resources utilization and process pollution emission reduction. To the best of our knowledge, there was no report about $\mathrm{Fe}-\mathrm{C}$ micro-electrolysis filler using SSBC for improving the biodegradability of a real PW. The SSBC/ZVI composites were characterized by scanning electron microscopy coupled to an energy dispersive X-ray spectrometry (SEM-EDX), fourier-transform infrared spectroscopy (FT-IR), x-ray diffraction (XRD) and specific surface area analysis. The pretreatment effect of $\mathrm{PW}$ was evaluated by $\mathrm{Bl}$ improvement.

\section{Materials And Methods}

\subsection{Materials and reagents}

Dewatered anaerobically digested SS with a moisture content of $82.1 \%$ (wt\%) was obtained from Chongqing Sino French Water Company. The digested SS was oven dried at about $105^{\circ} \mathrm{C}$ for $12 \mathrm{~h}$, and then milled and the particles with the size lower than $0.18 \mathrm{~mm}$ were collected. CSPW was provided by a chemical synthesis-based pharmacy company in Chongqing manufacturing cephalosporins and anticancer drugs. The wastewater used in this research was mainly generated from products manufacturing and equipment cleaning processes. Relevant characteristics of the CSPW were measured and the results were shown in Table 1. ZVI (300 mesh, 98.0\%) was purchased from Nangong Xindun Alloys spraying Co. Ltd. (China). $\mathrm{NaHCO}_{3}(\geq 98.5 \%$ purity) was purchased from Tianjin Kaitong Chemical Reagent Co., Ltd (China). Attapulgite clay (ATP) was purchased from Fuchen Chemical Reagents Co. Ltd (China). 
Table 1

Characteristics of the chemical synthesis

based pharmaceutical wastewater

\begin{tabular}{|ll|}
\hline Components & Concentration $(\mathrm{mg} / \mathrm{L})$ \\
\hline $\mathrm{COD}$ & 922 \\
\hline $\mathrm{BOD}_{5}$ & 157 \\
\hline TOC & 851 \\
\hline Suspended solids & 121 \\
\hline $\mathrm{TN}^{-}$ & 42 \\
\hline $\mathrm{NH}_{4}{ }^{+} \mathrm{N}$ & 18.2 \\
\hline $\mathrm{TP}^{-\mathrm{N}}$ & 17.5 \\
\hline Salinity & 29.3 \\
\hline $\mathrm{pH}$ & 6.26 \\
\hline
\end{tabular}

\subsection{Preparation of SSBC/ZVI composite}

SSBC with the yield of $64.3 \%$ (wt\%) was prepared as described in our previous research [14]. The obtained SSBC was milled and sieved again, and particles with the size below $0.15 \mathrm{~mm}$ were used for SSBC/ZVI composite preparation. The mass ratio of SSBC to ZVI was controlled at 2:1 due to the low carbon content of SSBC, and supplement level of ATP which acts as adhesive was according to the mechanical strength of the filler. In addition, certain amount of sodium bicarbonate was added to increase the porosity of the filler. For composite preparation, SSBC powder, ZVI powder, ATP and $\mathrm{NaHCO}_{3}$ as main raw material in a mass percentage of $50,25,20$ and 5 were granulated to particles with the diameter of 10 $\mathrm{mm}$ and then sintered at $800^{\circ} \mathrm{C}$ for $60 \mathrm{~min}$ under an oxygen-free circumstance. Before use, the filler was washed by deionized water with the solid liquid ratio of $1: 10$ for $12 \mathrm{~h}$ to remove the residues of poreforming agent.

\subsection{Characterization of SSBC/ZVI composite}

The surface area, porosity and pore volume of fresh and used SSBC/ZVI composite was determined by measuring the adsorption/desorption of $\mathrm{N}_{2}$ at $77 \mathrm{~K}$ according to the Brunauer-Emmett-Teller (BET) principle using a Micromeritics ASAP 2460 (Micromeritics, America). FT-IR was performed to identify the functional groups of SSBC/ZVI composite. To obtain the FT-IR spectra, samples were milled and mixed with $\mathrm{KBr}$ and then pressed into pellets. FT-IR spectra were recorded in the range of $4000-400 \mathrm{~cm}^{-1}$ with the resolution of 32 scans and $4 \mathrm{~cm}^{-1}$ on a Shimadzu IR Prestige-21 Spectrometer. Scanning electron microscopy (SEM, Zeiss Sigma 300, Germany) equipped with an energy dispersive spectrometer (EDX, XFlash 6, Bruker, Germany) detector was used to characterize the microscopic morphology of SSBC/ZVI composite. The crystal structures of SSBC and SSBC/ZVI composite were determined by XRD (X'Pert Pro 
MPD, Cu Ka radiation). The data in the $2 \theta$ range from $5^{\circ}$ to $90^{\circ}$ were collected with a scanning velocity of $10 \% \min$.

\subsection{Batch experiment for CSPW treatment}

Batch CSPW treatment was conducted in $250 \mathrm{~mL}$ of glass bottles placed in a water bath shaker at $25^{\circ} \mathrm{C}$ and $50 \mathrm{rpm}$. Each bottle contained $100 \mathrm{~mL}$ supernatant of CSPW after centrifugation at $2770 \mathrm{~g}$ RCF for 10 min. The initial $\mathrm{pH}$ was adjusted into desired values by sulfuric acid, and then the washed SSBC/ZVI composite was added into the reactor with different solid/liquid ratio. $1 \mathrm{~mL}$ of sample was taken at certain time intervals for analysis. After reaction, the SSBC/ZVI composite filler was taken out and dried at $105^{\circ} \mathrm{C}$ for 120 minutes under vacuum condition for materials characterization.

\subsection{Wastewater analysis}

Chemical oxygen demand (COD) of CSPW was measured by COD analyzer (Lianhua Technology Company, China) according to the users instructions. Total phosphorus (TP) in CSPW was measured by ammonium molybdate spectrophotometric method. Ammonia nitrogen $\left(\mathrm{NH}_{4}{ }^{+}-\mathrm{N}\right)$ concentration was measured by spectrophotometry method based on the Chinese standard method (HJ 535-2009 China). $\mathrm{pH}$ value was measured by a pH meter (Leichi Instrument Factory, Shanghai, China). Total organic carbon (TOC) and total nitrogen (TN) of CSPW was analyzed using a TOC analyzer (Shimadzu TOC-V CPH, Japan). Qualitative analysis of pollutants in CSPW was conducted on gas chromatography-mass spectrometry (Shimadzu GCMS-QP 2010 plus, Japan). Before analysis, the sample was centrifuged for 10 minutes at $8110 \mathrm{~g} \mathrm{RCF}$, and the supernatant was filtered through a $0.45 \mu \mathrm{m}$ membrane filter for analysis. The injection volume of each analysis was controlled at $1 \mathrm{uL}$ with split ratio of 10:1. The compounds were separated by Agilent DB-17 MS column (30 m×0.25 um×0.25 mm) with helium as the carrier gas. The injector was kept at $300^{\circ} \mathrm{C}$. The oven heating program was from $60^{\circ} \mathrm{C}$ (holding for $2 \mathrm{~min}$ ) to $300^{\circ} \mathrm{C}$ (holding for $5 \mathrm{~min}$ ) at a rate of $10^{\circ} \mathrm{C} / \mathrm{min}$. MS analysis was performed in full scan acquisition mode, in the mass range $29-500 \mathrm{~m} / \mathrm{z}$ at $1 \mathrm{scan} / \mathrm{s}$. The main pollutants were identified by comparing the mass spectra with the NIST library and similarity index calculation results by the software. In addition, the qualitative analysis results are also confirmed by comparing with the pollutant types in the environmental assessment reports.

\section{Results And Discussion}

\subsection{Characterization of SSBC/ZVI composite}

In order to characterize the characteristics of SSBC/ZBI composite filler and identify the mechanism of pollutant removal, fresh and used SSBC/ZVI composite was characterized by SEM-EDX, FT-IR, XRD and specific surface area analysis. The results and discussion about the characterization of materials were presented as follows.

\subsubsection{SEM-EDX characterization}


The microstructure of fresh SSBC/ZBI composite with 200 and 10000 times magnifications was presented in the SEM results in Fig. 1a. It can be found that the filler surface was heterogeneous due to the inconsistency of the particle size and density of the raw materials. The lamellar structure with relative smooth surface and short rod crystal pieces should be assigned to ferron particles and ATP, respectively. Previous research suggested that the surface of $\mathrm{Fe}^{0}$ in the fresh Fe-C micro-electrolytic filler is relatively smooth [15]. The ATP acts as the adhesive is short rod with $2 \mu \mathrm{m}$ in length and about $100 \mathrm{~nm}$ in diameter [16]. The rest amorphous material of the filler which contains rough, irregular structures with very few pores is SSBC [17]. EDX element contents analysis (shown in Fig. 1b) made clear to us that the filler contains iron, carbon and oxygen derived from the organic matter of SS, aluminum and potassium derived from the inorganic components of SS, and magnesium, silicon, and oxygen in ATP. Approximately, $32.15 \%$ iron and $13.56 \%$ carbon were measured in the SSBC/ZVI composites by EDX.

\subsubsection{FT-IR characterization}

FT-IR characterization was conducted to obtain the chemical structure and functional groups information of SSBC/ZVI composite, and the result was presented in Fig. 1c. The strong peak at about $3437 \mathrm{~cm}^{-1}$ was caused by $\mathrm{O}-\mathrm{H}$ stretching vibration [18]. The peak at $1632 \mathrm{~cm}^{-1}$ was preferentially assigned to the $\mathrm{C}$ $=0$ stretching vibration of carbonyl groups. The peak at $1063 \mathrm{~cm}^{-1}$ was probably caused by C-O-C stretching vibrations. The broad band at about $1035 \mathrm{~cm}^{-1}$ was mainly related to $\mathrm{C}-0$ stretching vibration [19]. The weak peak at $770 \mathrm{~cm}^{-1}$ was probably associated with $\mathrm{C}-\mathrm{H}$ bending vibration, while the peak at $779 \mathrm{~cm}^{-1}$ was correspond to the stretching vibration of aromatic $\mathrm{C}-\mathrm{H}$ groups [20]. Diversity of functional groups explains that SSBC and SSBC/ZVI can be used as adsorbent for multiple pollutants removal.

\subsubsection{XRD characterization}

$\mathrm{XRD}$ characterization was conducted to investigate the crystal structures of $\mathrm{Fe}^{0}$ and carbon on the surface of SSBC/ZVI composites. As the results shown in Fig. 1d, the SSBC/ZVI showed obvious peaks at $2 \theta$ of $44.9^{\circ}$, which corresponds to the reflection of $\mathrm{Fe}^{0}$ [21]. The weak bands at $2 \theta$ of $25.9^{\circ}$ indicated the carbonaceous structure presented in SSBC/ZVI [22]. The diffraction peaks of $\mathrm{SiO}_{2}$ were often appeared in SSBC as previous reports [23]. XRD analysis showed that $\mathrm{SiO}_{2}$ existed in both $\mathrm{SSBC}$ and $\mathrm{SSBC} / \mathrm{ZVI}$, and their content and morphology remained relatively stable.

\subsubsection{Specific surface area analysis}

The evolution of the BET surface area of SSBC/ZVI filler can be observed in Table 2. As can be seen, the BET surface area of fresh SSBC/ZVI was $32.35 \mathrm{~m}^{2} \llbracket \mathrm{g}^{-1}$, indicating the development of pores at the stage of carbonization and filler calcination. However, the BET surface area was smaller than commercially available Fe-C filler (165.638 $\mathrm{m}^{2} \llbracket \mathrm{g}^{-1}$ ) [24], which was due to the relative low specific surface area of SSBC [25]. 
Table 2

BET surface area and pore structure parameter of micro-electrolysis filler

\begin{tabular}{|c|c|c|c|}
\hline Samples & $\mathrm{S}_{\mathrm{BET}}$ & $\mathrm{V}_{\text {total }}\left(\mathrm{cm}^{-3} \llbracket \mathrm{g}^{-1}\right)$ & $\mathrm{D}_{\text {average }}(\mathrm{nm})$ \\
\hline$S S B C^{a}$ & 39.40 & 0.08 & 10.32 \\
\hline Fresh SSBC/ZVI b & 32.35 & 0.121 & 16.65 \\
\hline
\end{tabular}

\subsection{Evaluation of CSPW treatment effect under different condition}

The pollutants removal efficiency of micro-electrolysis was closely related to operation conditions, such as reaction time, initial $\mathrm{pH}$, filler dosage In this study, hydraulic retention time (HRT), initial $\mathrm{pH}$, and filler dosage were chosen as operational factors to discuss their influences on COD removal efficiency, and the results were illustrated in Fig. 2.

\subsubsection{Pollutants removal efficacy with different HRT}

HRT determines the reaction time of micro-electrolysis, and the influence of HRT on COD removal efficiency of CSPW was depicted in Fig. 2a. The COD remove process could be divided into three stages. In the first stage (0-20 min), 15.2\% of COD was removed within the 20 min and the COD removal rate was much higher than the residual two stages, which was due to the porous structure of SSBC/ZVI composite could adsorb the pollutants on its surface [26]. In the second stage (20-120 min), the growth of COD removal efficiency slowed down gradually. On the one hand, the adsorption capacity of SSBC/ZVI filler was limited, and the pollutants absorbed on the filler surface made a mass transfer resistance of electrons [5]. On the other hand, $\mathrm{Fe}^{2+}$ released in the anode might gathered on the filler surface, which further increased the mass transfer resistance [12]. In the third stage (120-180 min), the COD removal efficiency kept at relative constant value. As the reaction time extended, the $\mathrm{pH}$ value of the reaction system will rise to neutral or even alkaline. The micro-electrolysis reaction will halt at the neutral or alkaline condition due to the precipitated iron in the form of hydroxides attached on the filling surface,

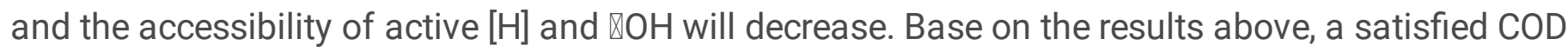
removal efficiency (30.5\%) can be achieved at HRT of $2 \mathrm{~h}$.

\subsubsection{Pollutants removal efficacy under different initial pH condition}

The $\mathrm{pH}$ value can affect the availability of active $[\mathrm{H}]$ and $\nabla \mathrm{OH}$ in the reaction system, which in turn affects the pollutants removal efficiency by iron-carbon micro-electrolysis. Five different $\mathrm{pH}$ levels $(1,3,5,7$ and 9) with HRT of $2 \mathrm{~h}$ and filler dosage of $100 \mathrm{~g} / \mathrm{L}$ were other condition, were operated to survey COD removal efficiency in batch experiments. The influence of $\mathrm{pH}$ on the pollutants removal efficiency was 
illustrated in Fig. 2b. With the increase of the $\mathrm{pH}$ from 1 to 3 , COD removal efficiency was marginally increased from 24.6-26.7\%. When the pH increased from 3 to 9 , the COD removal efficiency decreased gradually from $26.7-3.0 \%$. The micro-electrolysis was acid promoted reaction and mainly occurred between anode and cathode materials with the electron transfer. During the micro-electrolysis, the $\mathrm{Fe}^{0}$ was gradually corroded under the acid condition with electron lose. The electron transfer will be enhanced by increasing the $\mathrm{H}^{+}$concentration and the accessibility of active $[\mathrm{H}]$ and $\triangle \mathrm{OH}$ will be improved [27]. Large amount of $\mathrm{Fe}^{2+}$ will be generated gradually from $\mathrm{Fe} 0$ corrosion, and then the precipitate $\mathrm{Fe}(\mathrm{OH}) \mathrm{x}$ will be created as the $\mathrm{Fe}^{2+}$ oxidization and $\mathrm{H}^{+}$consumption. The iron hydroxides acts as the mass transfer resistance could be dissolved in the acidic condition, resulting in more reactive sites exposed. In neutral or alkaline condition, the micro electrolysis reaction will halt. It was generally accepted that the electron transfer rate would be inhibited remarkably in the alkaline condition, thus the COD removal efficiency continued to decline when the initial pH increased from 3.0 to 9.0. In order to achieve an effective COD removal efficiency, the initial $\mathrm{pH}$ of CPSW was adjusted to 3 before treatment.

\subsubsection{Pollutants removal efficacy with different SSBC/ZVI filler dosage}

The COD removal efficiency under different filler dosage was studied and the results were shown in Fig. 2c. As illustrated in Fig. 2c, COD removal efficiency increased gradually when the filler dosage increased from 50 to $150 \mathrm{~g} / \mathrm{L}$, and the maximum COD removal rate of $33.9 \%$ was achieved with $150 \mathrm{~g} / \mathrm{L}$ filler dosage. This could be explained by the increased surface area, reactive sites and $[\mathrm{H}]$ formation when the filler dosage increased [27]. Improved pollutants removal rate will be achieved when the electrode materials dosage increased because the pollutants degradation generally occurs at the active sites of the anode surface[28]. However, the pollutant removal efficiency will decrease when the electrode material dosage is too high, as the contacting area between electrode materials particles and wastewater would decrease. Moreover, micro-electrolysis reactions would be weakened when excess iron reacted with $\mathrm{H}^{+}$ [29]. The appropriate dosage of SSBC/ZVI composites was $100 \mathrm{~g} / \mathrm{L}$ with corresponding COD removal rate of $26.7 \%$.

\subsection{Characterization of pollutants removal by GC-MS}

To clarify the pollutants degradation pathways, GC-MS analysis was used to examine the pollutants and derived intermediates in CSPW. The pollutants species and derived intermediates in CSPW were listed in Table 3. Total of 17 main organic pollutant species were detected in raw CSPW, which were the major contributors to COD. For the untreated CSPW, 17 main organic pollutants could be divided into 7 types including alcohols (No. 1-5), ketones (No. 6), esters (No. 7-9), intermediate (No. 10), amines (No. 1215), nitriles (N0.17) and pyridines(No. 18, 20). After micro-electrolysis treatment for 120 min, the number of main pollutant species increased to 23 . Specifically, there was no pollutant species were completely removed and 6 new pollutant species were generated after treatment. The above results suggested that the COD of CSPW could be partially removed owing to the abatement of organic pollutant species in SSBC/ZVI treatment. It was obvious that most pollutants presented in CSPW were degraded into smaller 
molecules after micro-electrolysis treatments, and the above discoveries supported the COD removal by SSBC/ZVI treatment.

Table 3

Main pollutant species detected by GC-MS before and after micro-electrolysis treatments

\begin{tabular}{|c|c|c|c|c|c|}
\hline \multirow[t]{2}{*}{ No. } & \multirow[t]{2}{*}{ Organic compounds name } & \multirow[t]{2}{*}{ Category } & \multirow{2}{*}{$\begin{array}{l}\text { MW } \\
\text { (g/mol) }\end{array}$} & \multicolumn{2}{|c|}{ Peak area $\left(\times 10^{5}\right)$} \\
\hline & & & & Raw CSPW & Treated CSPW \\
\hline 1 & Methanol & Alcohols & 32 & 94.43 & 66.74 \\
\hline 2 & Ethanol & Alcohols & 46 & 105.24 & 72.38 \\
\hline 3 & Isopropanol & Alcohols & 60 & 59.02 & 35.77 \\
\hline 4 & 1-Butanol & Alcohols & 74 & 16.61 & 7.59 \\
\hline 5 & 3-pentanol & Alcohols & 88 & 16.16 & 6.43 \\
\hline 6 & Acetone & Ketones & 58 & 23.57 & 10.62 \\
\hline 7 & Methyl acetate & Esters & 74 & 7.55 & 2.96 \\
\hline 8 & Ethyl acetate & Esters & 88 & 25.12 & 12.18 \\
\hline 9 & Methyl acetoacetate & Esters & 116 & 10.82 & 7.24 \\
\hline 10 & 4-hydroxy-4-methyl-2-pentanone & Intermediate & 116 & 13.99 & 2.89 \\
\hline 11 & Formamide & Amides & 45 & ND & 2.62 \\
\hline 12 & Aminotoluene & Amines & 107 & 4.31 & 1.32 \\
\hline 13 & Diisopropylethylamine & Amines & 129 & 55.39 & 10.36 \\
\hline 14 & Triethylamine & Amines & 101 & 19.30 & 3.68 \\
\hline 15 & $\mathrm{~N}, \mathrm{~N}$-Dimethylformamide & Amines & 73 & 4.55 & 2.08 \\
\hline 16 & Ethylamine & Amines & 45 & ND & 1.39 \\
\hline 17 & Acetonitrile & Nitriles & 41 & 8.27 & 8.14 \\
\hline 18 & 2,3-Cyclopenteno pyridine & Pyridines & 119 & 7.25 & 3.83 \\
\hline 19 & 2,6-Lutidine & Pyridines & 107 & ND & 2.89 \\
\hline 20 & 2-Dimethylaminopyridine & Pyridines & 122 & 3.22 & 1.65 \\
\hline 21 & 2-Aminopyridine & Pyridines & 94 & ND & 1.14 \\
\hline 22 & p-Nitrotoluene & Benzenes & 137 & ND & 2.37 \\
\hline 23 & Formic acid & Acids & 60 & ND & 7.25 \\
\hline
\end{tabular}


In order to clarify the pollutants removal mechanism by the SSBC/ZVI micro-electrolysis system, the used SSBC/ZVI filler and iron sludge were characterized by EDX and FTIR firstly, and the results were shown in Fig. 3. The EDX analysis was carried out for used SSBC/ZVI composite to show the change of the filler after CSPW treatment (Fig. 3a). It is shown in EDX spectra that after SCPW treatment, the content of Fe in the composite decreased obviously while the content of carbon increased correspondingly, indicating that a great amount of $\mathrm{Fe}^{0}$ was consumed after micro-electrolysis treatment.

The FTIR analysis of used SSBC/ZVI composite was also conducted to show the change of the filler after CSPW treatment (Fig. 3b). Compared with the FTIR spectrum of fresh SSBC/ZVI (Fig. 1c), several new absorption peaks were found in the FTIR spectrum of used SSBC/ZVI. The peak at $1420 \mathrm{~cm}^{-1}$ was caused by $\mathrm{C}=\mathrm{O}$ symmetric stretching vibration. The peak at $1320 \mathrm{~cm}^{-1}$ corresponds to $\mathrm{C}-\mathrm{N}$ stretching vibration of amines. In addition, the peak at $1063 \mathrm{~cm}^{-1}$ covered by the two strong peaks at $1035 \mathrm{~cm}^{-1}$ and $986 \mathrm{~cm}^{-1}$. The peak at $986 \mathrm{~cm}^{-1}$ corresponds to $\mathrm{C}-\mathrm{O}-\mathrm{C}$ vibrations of proteins or polysaccharides. The peak at $689 \mathrm{~cm}^{-1}$ was ascribed to $C-C l$ stretching vibration. The peaks at $513 \mathrm{~cm}^{-1}$ and $472 \mathrm{~cm}^{-1}$ were associated with $\mathrm{M}-\mathrm{X}$ ( $\mathrm{M}$-metal, $\mathrm{X}$-halogen) stretching vibration. Diversity of functional groups in SSBC/ZVI explains SSBC/ZVI can be utilized for the adsorption removal of multiple pollutants in CSPW. These new absorption peaks in FTIR spectra of SSBC/ZVI indicated that the pollutants in CSPW can be removed through adsorption. In addition, in order to investigate the pollutants removal by SSBC adsorption, separate adsorption experiment was also conducted. The results of adsorption experiments showed that $5.2 \%$ of COD could be removed within $2 \mathrm{~h}$ under neutral $\mathrm{pH}$ conditions and $100 \mathrm{~g} / \mathrm{L}$ SSBC/ZVI dosage. SSBC/ZVI showed limited adsorption removal rate of pollutants in CSPW due to the low absorption capacity of SSBC [30].

Iron sludge containing the ferrous and ferric hydroxides was formed by oxidation and precipitation of $\mathrm{Fe}^{2+}$ released from anode. Pollutants can be removed by iron sludge with the combinational effects of enmeshment, co-precipitation, adsorption and interparticle bridging in the process of coagulation [13]. FTIR characterization of iron sludge (Fig. 3c) showed that there were some new absorption peaks in addition to the infrared absorption peaks produced by the detrital materials exfoliated from SSBC/ZVI. The new FTIR peak at $3055 \mathrm{~cm}^{-1}$ caused by the $\mathrm{C}-\mathrm{H}$ vibration of ethyl and methylene groups suggested that the pollutants with aliphatic chain could be removed by iron sludge flocculation. The new peak at $1617 \mathrm{~cm}^{-1}$ suggested that compounds containing benzene ring could be also removed by iron sludge flocculation. However, some pollutants may volatilize during the drying process of sample preparation for FTIR characterization and cannot be detected.

Figure 4 proposed the removal mechanisms of pollutants in CSPW treated by SSBC/ZVI microelectrolysis system. The mechanism of pollutants removal includes the adsorption of SSBC and the coagulation as discussed above, as well as micro-electrolysis [13, 31]. In SSBC/ZVI micro-electrolysis system, SSBC acts as the cathode in which $\mathrm{H}^{+}$obtain electrons to generate [H] for pollutants reduction. $\mathrm{Fe}^{\mathrm{O}}$ acts as the anode of micro-electrolysis system, and $\mathrm{Fe}^{\mathrm{O}}$ loses electrons to form $\mathrm{Fe}^{2+}$. $\mathrm{OH}$ radical formed in anode can oxide the pollutants to intermediates or $\mathrm{CO}_{2}$ and $\mathrm{H}_{2} \mathrm{O}$. In terms of newly generated 
organic species as shown in Table 3, the possible formation pathway can be illustrated as follows. Ethylamine (No. 16) was formed by de-isopropyl and de-ethyl of diisopropylethylamine (No. 13) and triethylamine (No. 14), respectively. Formamide (No. 11) may be an intermediate formed by demethylation of N,N-dimethylformamide (No. 15). 2,6-lutidine (No. 19) may be an intermediate formed by heterocyclic ring opening of 2,3-cyclopenteno pyridine (No. 18). 2-Aminopyridine (No. 21) was formed by the demethylation of 2-Dimethylaminopyridine (No. 20), and p-Nitrotoluene (No. 22) was formed by the reduction of aminotoluene (No. 12).

\subsection{Reusability of SSBC/ZVI composite filler}

Previous researches reported that the micro electrolysis fillers can be gradually hardened after the repeated running process owing to the passivation, blockage, and mass transport limitation of the filler surface [5,32]. Long-term run of SSBC/ZVI system for CSPW treatment was conducted to verify whether the fillers could become harden. The operation conditions for 6 runs within 720 min were set as follows with the initial $\mathrm{pH}$ of $3, \mathrm{HRT}$ of $2 \mathrm{~h}$, filler dosage of $100 \mathrm{~g} / \mathrm{L}$. The COD removal efficiency and BI values were presented in Fig. 5. The COD removal efficiency in SSBC/ZVI was stable and performed well within the first 5 runs. While for the sixth run, COD removal efficiency decreased gradually from 29.1 to $23.9 \%$, owing to the surface passivation, blockage, and mass transport limitation. The results suggested that SSBC/ZVI systems had relative high stability and excellent reusability for COD removal from CSPW. The COD of SSBC/ZVI treated CSPW was still high and the effluent cannot be discharged directly. We explore the feasibility using SSBC/ZVI as pretreatment technology before biochemical treatment, since microelectrolysis pretreatment could increase the BI value of wastewater, which is helpful for subsequent biological processes [33]. The BI value is normally used to express the biodegradability of wastewater. When $\mathrm{BI}$ value is higher than 0.3 , the wastewater usually exhibits a better biodegradability [34]. The $\mathrm{BI}$ values after different operation runs were analyzed and the results were shown in Fig. 5. Raw CSPW cannot be biodegraded according to the low BI value of 0.17 . Improvement in biodegradability was achieved with SSBC/ZVI micro electrolysis system in the first 4 run operation, and $\mathrm{BI}$ value increased from initial 0.17 to $0.39,0.36,0.36$ and 0.32 , respectively. The results indicated the biodegradability of SSBC/ZVI system treated CSPW was enhanced. However, the BI value decreased to 0.29 and 0.27 after the 5th and 6th run operation. Therefore, after 4 run operation using SSBC/ZVI for CSPW pretreatment, necessary measures should be taken to ensure the stability of the system.

\subsection{Comparison of different pretreatments of CSPW for biodegradability improvement}

Table 4 shows a comparison of different advanced oxidation processes (AOPs) as pretreatment methods of real chemical synthesis-based pharmaceutical wastewater, which mainly includes ozone oxidation, inner electrolysis, Fenton oxidation, catalytic oxidation and the combination technologies. The pretreatment effect of SSBC/ZVI system on real pharmaceutical wastewater is equivalent to the reported methods such as CoMnAl-CMO- $\mathrm{Al}_{2} \mathrm{O}_{3} / \mathrm{H}_{2} \mathrm{O}_{2}$ oxides catalyst process [35], microwave assisted Fenton like process [36], but higher than the process using an $\mathrm{Fe}_{2} \mathrm{O}_{3} / \mathrm{SBA}-15$ nano composite catalyst [37]. It should be emphasized that the raw material of SSBC/ZVI composites filler is waste sewage sludge, and the 
reaction process does not require the addition of chemical reagents such as $\mathrm{H}_{2} \mathrm{O}_{2}$. These results indicated that SSBC/ZVI micro electrolysis was suitable for CSPW pretreatment.

Table 4

Comparative analysis of pretreatment methods for biodegradability improvement of real chemical synthesis-based pharmaceutical wastewater

\begin{tabular}{|c|c|c|c|c|}
\hline Wastewater type & $\begin{array}{l}\text { Physicochemical } \\
\text { characteristics }\end{array}$ & Pretreatment methods & $\begin{array}{l}\text { Biodegradability } \\
\text { enhancement }\end{array}$ & References \\
\hline $\begin{array}{l}\text { Cephalosporins, } \\
\text { and anticancer } \\
\text { drugs synthesis } \\
\text { wastewater }\end{array}$ & $916 \mathrm{mg} / \mathrm{L} \mathrm{COD}$ & $\begin{array}{l}\text { SSBC/ZVI micro- } \\
\text { electrolysis }\end{array}$ & $\begin{array}{l}\mathrm{BI} \text { value enhanced } \\
\text { from } 0.17 \text { to } 0.39\end{array}$ & This study \\
\hline $\begin{array}{l}\text { Paracetamol } \\
\text { manufacturing } \\
\text { wastewater }\end{array}$ & $1390 \mathrm{mg} / \mathrm{L} \mathrm{COD}$ & $\mathrm{O}_{3} / \mathrm{nZVI}$ & $\begin{array}{l}\text { BI value enhanced } \\
\text { from } 0.18 \text { to } 0.63\end{array}$ & [3] \\
\hline Not stated & $\begin{array}{l}60000-80000 \\
\mathrm{mg} / \mathrm{L} \mathrm{COD}\end{array}$ & $\begin{array}{l}\text { CoMnAl-CMO- } \\
\mathrm{Al}_{2} \mathrm{O}_{3} / \mathrm{H}_{2} \mathrm{O}_{2} \text { oxides } \\
\text { catalyst }\end{array}$ & $\begin{array}{l}\text { BI value increased } \\
\text { from } 0.173 \text { to } \\
0.464\end{array}$ & [35] \\
\hline $\begin{array}{l}\text { Active } \\
\text { pharmaceutical } \\
\text { ingredients } \\
\text { manufacturing } \\
\text { wastewater }\end{array}$ & $7010 \mathrm{mg} / \mathrm{L} \mathrm{COD}$ & Fenton & $\begin{array}{l}\text { Biodegradability } \\
\text { (TOC removal by } \\
\text { biological } \\
\text { processes) } \\
\text { increased from } \\
17-97 \%\end{array}$ & [7] \\
\hline $\begin{array}{l}\text { Etodolac } \\
\text { manufacturing } \\
\text { wastewater }\end{array}$ & $\begin{array}{l}\text { Up to } 7500 \mathrm{mg} / \mathrm{L} \\
\text { of COD }\end{array}$ & Ozonation process & $\begin{array}{l}\text { COD removal } \\
\text { efficiency } \\
\text { increased from } \\
50 \% \text { to } 85-90 \%\end{array}$ & [38] \\
\hline $\begin{array}{l}\text { Steroid hormone } \\
\text { synthesis } \\
\text { wastewater }\end{array}$ & $\begin{array}{l}13189-16644 \\
\mathrm{mg} / \mathrm{L} \mathrm{COD}\end{array}$ & $\begin{array}{l}\text { Combined interior } \\
\text { micro-electrolysis and } \\
\text { Fenton oxidation } \\
\text { coagulation }\end{array}$ & $\begin{array}{l}\text { BI value increased } \\
\text { from } 0.21 \text { to } 0.59\end{array}$ & [5] \\
\hline $\begin{array}{l}\text { Cephalosporin } \\
\text { synthesis } \\
\text { wastewater }\end{array}$ & $\begin{array}{l}2169 \mathrm{mg} / \mathrm{L} \text { of } \\
\text { COD }\end{array}$ & $\begin{array}{l}\text { Microwave-assisted } \\
\text { Fenton-like (MW- } \\
\text { Fenton-like) process }\end{array}$ & $\begin{array}{l}\mathrm{BI} \text { value increased } \\
\text { from } 0.23 \text { to } 0.40\end{array}$ & [36] \\
\hline $\begin{array}{l}\text { Mixed chemical } \\
\text { wastewater }\end{array}$ & $\begin{array}{l}400-800 \mathrm{mg} / \mathrm{L} \\
\text { of COD }\end{array}$ & Internal electrolysis & $\begin{array}{l}\text { BI value increased } \\
\text { from } 0.3 \text { to } 0.6\end{array}$ & [11] \\
\hline $\begin{array}{l}\text { Cardiovascular } \\
\text { and venous } \\
\text { diseases drugs } \\
\text { synthesis } \\
\text { wastewater }\end{array}$ & $\begin{array}{l}1901 \mathrm{mg} / \mathrm{L} \text { of } \\
\text { COD }\end{array}$ & $\begin{array}{l}\text { Heterogeneous } \\
\text { catalytic wet peroxide } \\
\text { oxidation (CWPO) } \\
\text { process using an } \\
\mathrm{Fe}_{2} \mathrm{O}_{3} / \mathrm{SBA}-15 \text { nano } \\
\text { composite catalyst }\end{array}$ & $\begin{array}{l}\text { BI value increased } \\
\text { from } 0.2 \text { to } 0.3\end{array}$ & [37] \\
\hline
\end{tabular}

\section{Conclusions}


In this study, SSBC was used to establish micro-electrolysis systems for actual pharmaceutical wastewater pretreatment. The optimal parameters of SSBC/ZVI micro electrolysis system were HRT of 2 $\mathrm{h}$, initial $\mathrm{pH}$ of 3 and the filler dosage of $100 \mathrm{~g} / \mathrm{L}$. The COD removal rate was $30.5 \%$. According to the characterization results of SEM-EDS, FTIR, XRD analysis of raw and used SSBC/ZVI composites, and the GC-MS analysis of raw and treated CSPW, the removal of pollutants mainly includes adsorption, micro electrolysis and flocculation. Besides, SSBC/ZVI possessed stability in repeated runs for BI improvement of CSPW. Therefore, SSBC/ZVI micro-electrolysis could be considered as a cost-effective, feasible, and promising method for real pharmaceutical wastewater pretreatment.

\section{Declarations}

\section{Data availability}

The datasets used and/or analyzed during the current study are available from the corresponding author on reasonable request.

\section{Author contribution}

Gaoxiang Qi performed the preparation of materials, experiments design and manuscript preparation. Xiaobo Wang conducted experiments. Xuecheng Liu analyzed the samples. Yu Shen discussed the results and revised the manuscript.

\section{Funding}

This work was supported by China Postdoctoral Science Foundation (2019M653318), Innovation Group of New Technologies for Industrial Pollution Control of Chongqing Education Commission (CXQT19023), Chongqing Municipal Education Commission Foundation (KJQN201900820), Open Funding of Chongqing Technology and Business University (KFJJ2018103).

\section{Ethics approval and consent to participate}

No animals or human subjects were used in this research.

\section{Consent for publication}

Our manuscript does not contain any individual data in any form.

\section{Conflict of interest}


The authors declare no competing interests.

\section{References}

1. Bagchi, S., Behera, M.: Pharmaceutical wastewater treatment in microbial fuel cell, in Integrated Microbial Fuel Cells for Wastewater Treatment. Elsevier. 135-155 (2020)

2. Lan, B., Huang, R., Li, L., Yan, H., Liao, G., Wang, X., Zhang, Q.: Catalytic ozonation of p-chlorobenzoic acid in aqueous solution using Fe-MCM-41 as catalyst. Chem. Eng. J. 219, 346-354 (2013)

3. Malik, S.N., Khan, S.M., Ghosh, P.C., Vaidya, A.N., Kanade, G., Mudliar, S.N.: Treatment of pharmaceutical industrial wastewater by nano-catalyzed ozonation in a semi-batch reactor for improved biodegradability. Sci. Total Environ. 678, 114-122 (2019)

4. Ismail, Z.Z., Habeeb, A.A.: Experimental and modeling study of simultaneous power generation and pharmaceutical wastewater treatment in microbial fuel cell based on mobilized biofilm bearers. Renewable Energy 101, 1256-1265 (2017)

5. Xu, X., Cheng, Y., Zhang, T., Ji, F., Xu, X.: Treatment of pharmaceutical wastewater using interior microelectrolysis/Fenton oxidation-coagulation and biological degradation. Chemosphere 152, 23-30 (2016)

6. Huang, S., Shi, X., Bi, X., Lee, L.Y., Ng, H.Y.: Effect of ferric hydroxide on membrane fouling in membrane bioreactor treating pharmaceutical wastewater. Bioresour. Technol. 292, 121852 (2019)

7. Martínez, F., Molina, R., Rodríguez, I., Pariente, M., Segura, Y., Melero, J.: Techno-economical assessment of coupling Fenton/biological processes for the treatment of a pharmaceutical wastewater. J. Environ. Chem. Eng. 6(1), 485-494 (2018)

8. Zhang, F., Yue, Q., Gao, Y., Wang, W., Gao, B., Wang, C.: Application for oxytetracycline wastewater pretreatment by Fe-C-Ni catalytic cathodic-anodic-electrolysis granular fillers from rare-earth tailings. Ecotox. Environ. Safe 164, 641-647 (2018)

9. Wang, K., Liu, S., Zhang, Q., He, Y.: Pharmaceutical wastewater treatment by internal microelectrolysis-coagulation, biological treatment and activated carbon adsorption. Environ. Technol. 30(13), 1469-1474 (2009)

10. Zhu, Q., Guo, S., Guo, C., Dai, D., Jiao, X., Ma, T., Chen, J.: Stability of Fe-C micro-electrolysis and biological process in treating ultra-high concentration organic wastewater. Chem. Eng. J. 255, 535540 (2014)

11. Sun, L., Wang, C., Ji, M., Kong, X.: Treatment of mixed chemical wastewater and the agglomeration mechanism via an internal electrolysis filter. Chem. Eng. J. 215, 50-56 (2013)

12. Sun, Z., Xu, Z., Zhou, Y., Zhang, D., Chen, W.: Effects of different scrap iron as anode in Fe-C microelectrolysis system for textile wastewater degradation. Environ. Sci. Pollut. Res. 26(26), 26869-26882 (2019)

13. Yang, Z., Ma, Y., Liu, Y., Li, Q., Zhou, Z., Ren, Z.: Degradation of organic pollutants in near-neutral pH solution by Fe-C micro-electrolysis system. Chem. Eng. J. 315, 403-414 (2017) 
14. Qi, G., Li, C., Mei, Y., Xu, W., Shen, Y., Gao, X.: A new strategy for nitrogen containing compounds recovery from gaseous products during sewage sludge pyrolysis under vacuum condition. J. Environ. Chem. Eng. 8(5), 104452 (2020)

15. Xu, Z., Gao, Y., Sun, Z., Zhang, D., Zhou, Y., Chen, W.: New insights into the reinforced reduction performance of $\mathrm{Fe} / \mathrm{C}$ internal electrolysis activated by persulfate for $\mathrm{p}$-nitrophenol removal. Chemosphere 254, 126899 (2020)

16. Huang, R., Lin, Q., Zhong, Q., Zhang, X., Wen, X., Luo, H.: Removal of Cd (II) and Pb (II) from aqueous solution by modified attapulgite clay. Arabian J. Chem. 13(4), 4994-5008 (2020)

17. Srinivasan, P., Sarmah, A.K., Smernik, R., Das, O., Farid, M., Gao, W.: A feasibility study of agricultural and sewage biomass as biochar, bioenergy and biocomposite feedstock: production, characterization and potential applications. Sci. Total Environ. 512, 495-505 (2015)

18. Shu, R., Wang, Y., Zhong, H.: Biochar amendment reduced methylmercury accumulation in rice plants. J. Hazard. Mater. 313, 1-8 (2016)

19. Lin, Q., Cheng, H., Chen, G.: Preparation and characterization of carbonaceous adsorbents from sewage sludge using a pilot-scale microwave heating equipment. J. Anal. Appl. Pyrolysis 93, 113-119 (2012)

20. Cui, X., Hao, H., Zhang, C., He, Z., Yang, X.: Capacity and mechanisms of ammonium and cadmium sorption on different wetland-plant derived biochars. Sci. Total Environ. 539, 566-575 (2016)

21. Zhang, C., Li, F., Wen, R., Zhang, H., Elumalai, P., Zheng, Q., Chen, H., Yang, Y., Huang, M., Ying, G.: Heterogeneous electro-Fenton using three-dimension NZVI-BC electrodes for degradation of neonicotinoid wastewater. Water Res. 182, 115975 (2020)

22. Liu, Y., Wang, C., Sui, Z., Zou, D.: Degradation of chlortetracycline using nano micro-electrolysis materials with loading copper. Sep. Purif. Technol. 203, 29-35 (2018)

23. Liu, L., Huang, L., Huang, R., Lin, H., Wang, D.: Immobilization of heavy metals in biochar derived from co-pyrolysis of sewage sludge and calcium sulfate. J. Hazard. Mater. 403, 123648 (2021)

24. Huang, C., Peng, F., Guo, H.-J., Wang, C., Luo, M.-T., Zhao, C., Xiong, L., Chen, X.-F., Chen, X.-D.: Efficient COD degradation of turpentine processing wastewater by combination of Fe-C micro-electrolysis and Fenton treatment: long-term study and scale up. Chem. Eng. J. 351, 697-707 (2018)

25. Yuan, H., Lu, T., Zhao, D., Huang, H., Noriyuki, K., Chen, Y.: Influence of temperature on product distribution and biochar properties by municipal sludge pyrolysis. J. Mater. Cycles Waste Manage. 15(3), 357-361 (2013)

26. Huang, D., Yue, Q., Fu, K., Zhang, B., Gao, B., Li, Q., Wang, Y.: Application for acrylonitrile wastewater treatment by new micro-electrolysis ceramic fillers. Desalin. Water Treat. 57(10), 4420-4428 (2016)

27. Lai, B., Zhang, Y., Chen, Z., Yang, P., Zhou, Y., Wang, J.: Removal of p-nitrophenol (PNP) in aqueous solution by the micron-scale iron-copper (Fe/Cu) bimetallic particles. Appl. Catal., B 144, 816-830 (2014)

28. Liu, L., He, D., Pan, F., Huang, R., Lin, H., Zhang, X.: Comparative study on treatment of methylene blue dye wastewater by different internal electrolysis systems and COD removal kinetics, thermodynamics 
and mechanism. Chemosphere 238, 124671 (2020)

29. Zhang, Q.: Treatment of oilfield produced water using Fe/C micro-electrolysis assisted by zero-valent copper and zero-valent aluminium. Environ. Technol. 36(4), 515-520 (2015)

30. Singh, S., Kumar, V., Dhanjal, D.S., Datta, S., Bhatia, D., Dhiman, J., Samuel, J., Prasad, R., Singh, J.: A sustainable paradigm of sewage sludge biochar: Valorization, opportunities, challenges and future prospects. J. Cleaner Prod. 269(1), 122259 (2020)

31. Zhang, X. B., Dong, W. Y., Sun, F. Y, Yang, W., Dong, J.: Degradation efficiency and mechanism of azo dye RR2 by a novel ozone aerated internal micro-electrolysis filter. J. Hazard. Mater. 276, 77-87 (2014)

32. Lai, B., Zhou, Y., Wang, J., Zhang, Y., Chen, Z.: Passivation process and the mechanism of packing particles in the Fe0/GAC system during the treatment of ABS resin wastewater. Environ. Technol. 35(8), 973-983 (2014)

33. Jin, Y., Yue, Q., Yang, K., Wu, S., Li, S., Gao, B., Gao, Y.: Pre-treatment of pyridine wastewater by new cathodic-anodic-electrolysis packing. J. Environ. Sci. 63, 43-49 (2018)

34. Raut-Jadhav, S., Badve, M.P., Pinjari, D.V., Saini, D.R., Sonawane, S.H., Pandit, A.B.: Treatment of the pesticide industry effluent using hydrodynamic cavitation and its combination with process intensifying additives $\left(\mathrm{H}_{2} \mathrm{O}_{2}\right.$ and ozone). Chem. Eng. J. 295, 326-335 (2016)

35. Ling, L., Liu, Y., Pan, D., Lyu, W., Xu, X., Xiang, X., Lyu, M., Zhu, L.: Catalytic detoxification of pharmaceutical wastewater by Fenton-like reaction with activated alumina supported CoMnAl composite metal oxides catalyst. Chem. Eng. J. 381, 122607 (2020)

36. Qi, X., Li, Z.: Efficiency optimization of a microwave-assisted Fenton-like process for the pretreatment of chemical synthetic pharmaceutical wastewater. Desalin. Water Treat. 57(25), 11756-11764 (2016)

37. Melero, J.A., Martínez, F., Botas, J.A., Molina, R., Pariente, M.I.: Heterogeneous catalytic wet peroxide oxidation systems for the treatment of an industrial pharmaceutical wastewater. Water Res. 43(16), 4010-4018 (2009)

38. Kaya, Y., Bacaksiz, A.M., Bayrak, H., Gönder, Z.B., Vergili, I., Hasar, H., Yilmaz, G.: Treatment of chemical synthesis-based pharmaceutical wastewater in an ozonation-anaerobic membrane bioreactor (AnMBR) system. Chem. Eng. J. 322, 293-301 (2017)

\section{Figures}



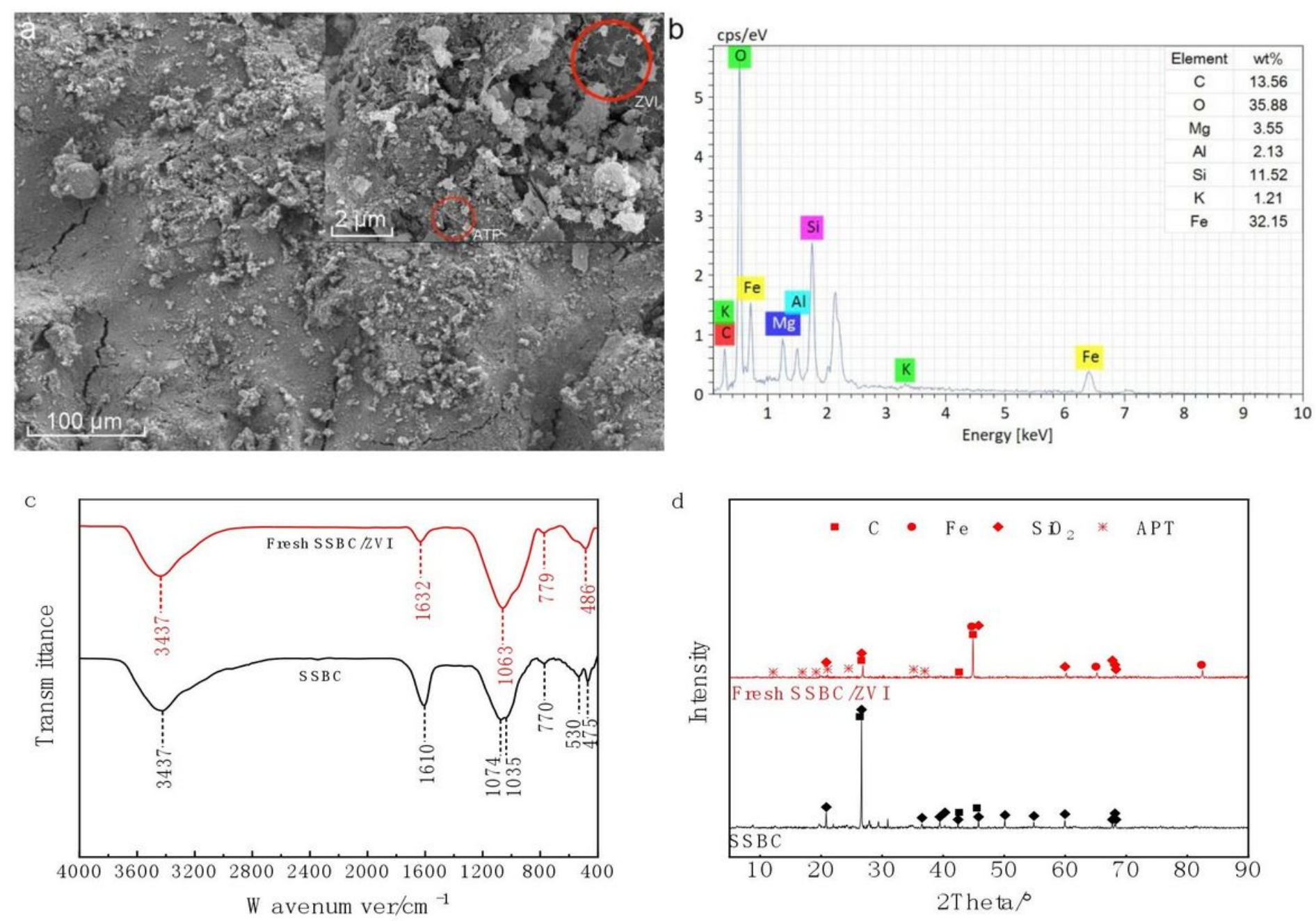

\section{Figure 1}

SEM image (a), Energy dispersive X-ray spectroscopy (b), FT-IR spectra (c), and XRD spectra (d) of fresh SSBC/ZVI composite filler 

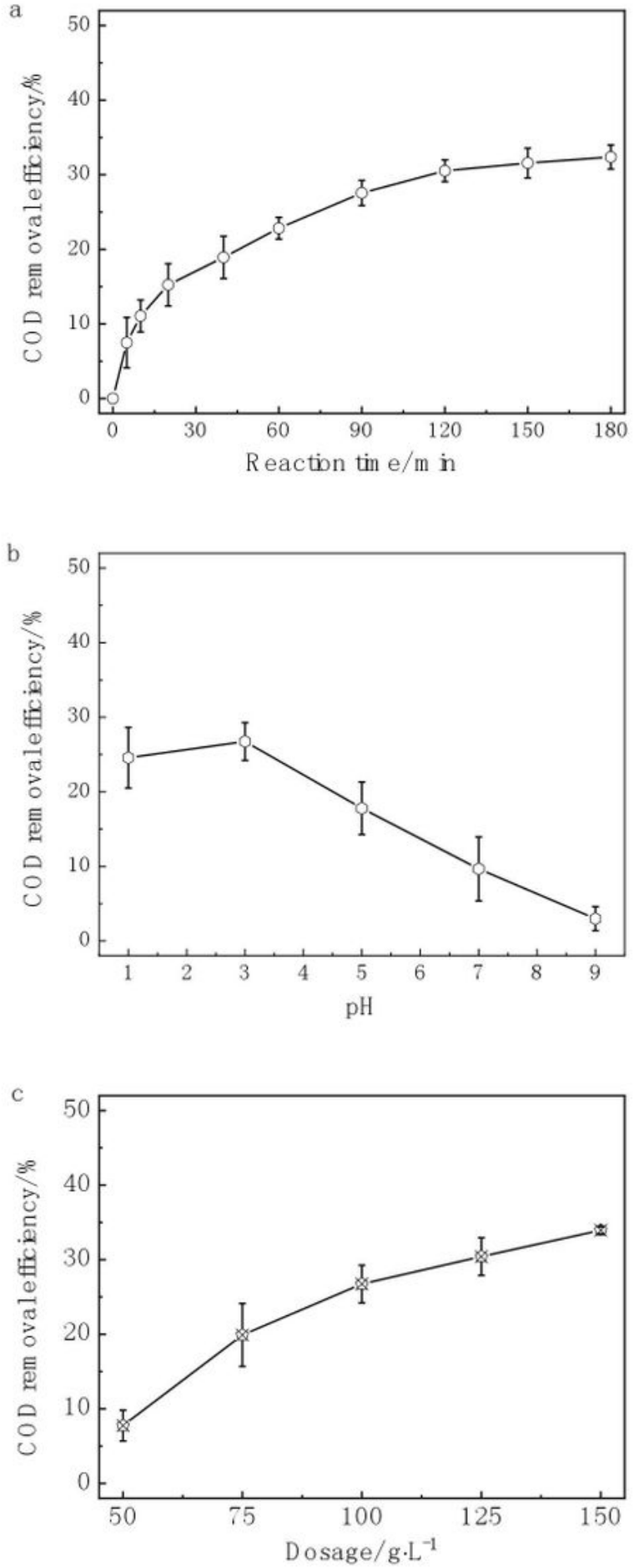

Figure 2

Effect of (a) reaction time, (b) initial $\mathrm{pH}$ and (c) SSBC/ZVI composite fillers dosage on the COD removal efficiency (a, the initial pH of 3.0 and fillers dosage of $100 \mathrm{~g} / \mathrm{L} ; \mathrm{b}$, the reaction time of $120 \mathrm{~min}$ and fillers dosage of $100 \mathrm{~g} / \mathrm{L} ; \mathrm{c}$, the initial $\mathrm{pH}$ of 3.0 and reaction time of $120 \mathrm{~min}$ ) 

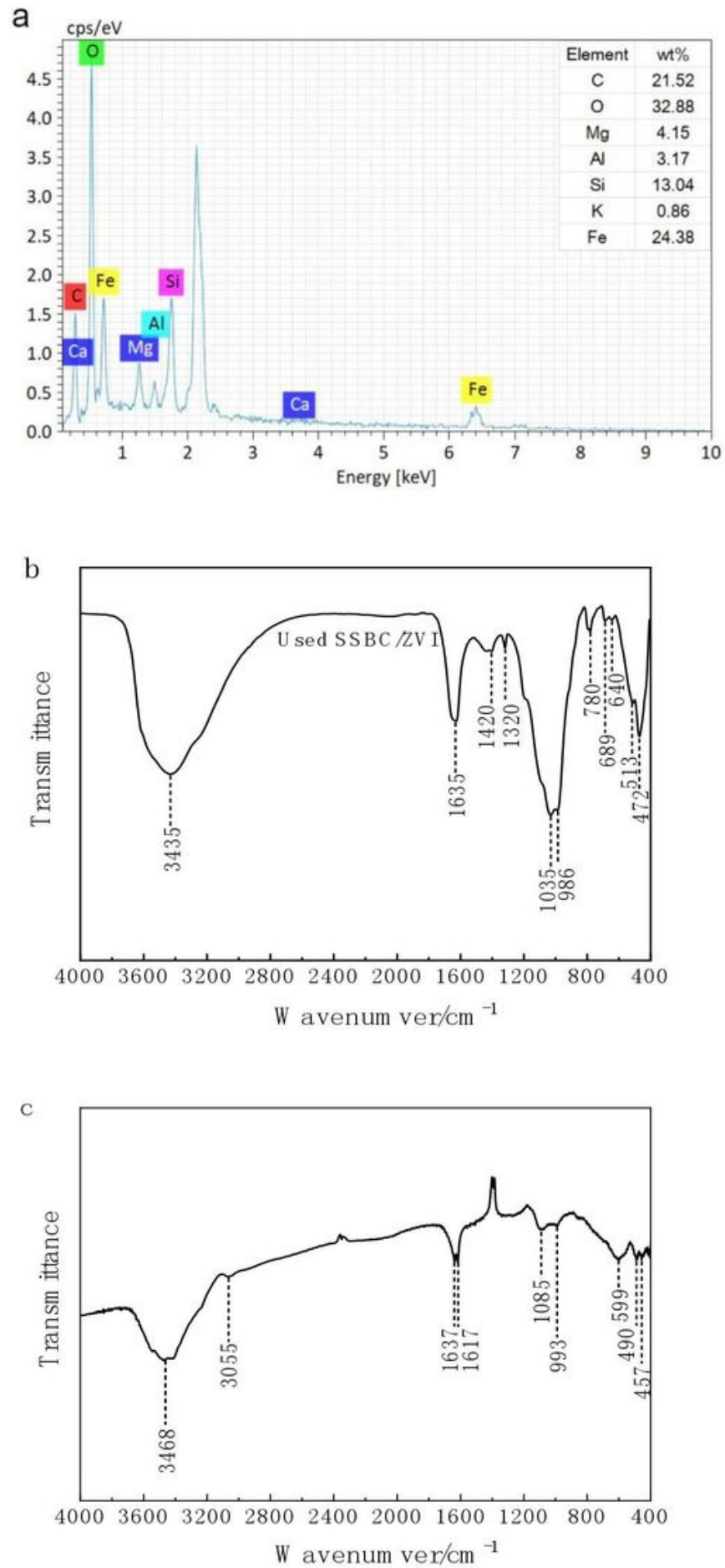

\section{Figure 3}

Energy dispersive X-ray spectroscopy (a), FT-IR spectra (b) of used SSBC/ZVI and FT-IR spectra (c) of micro-electrolytic sludge 


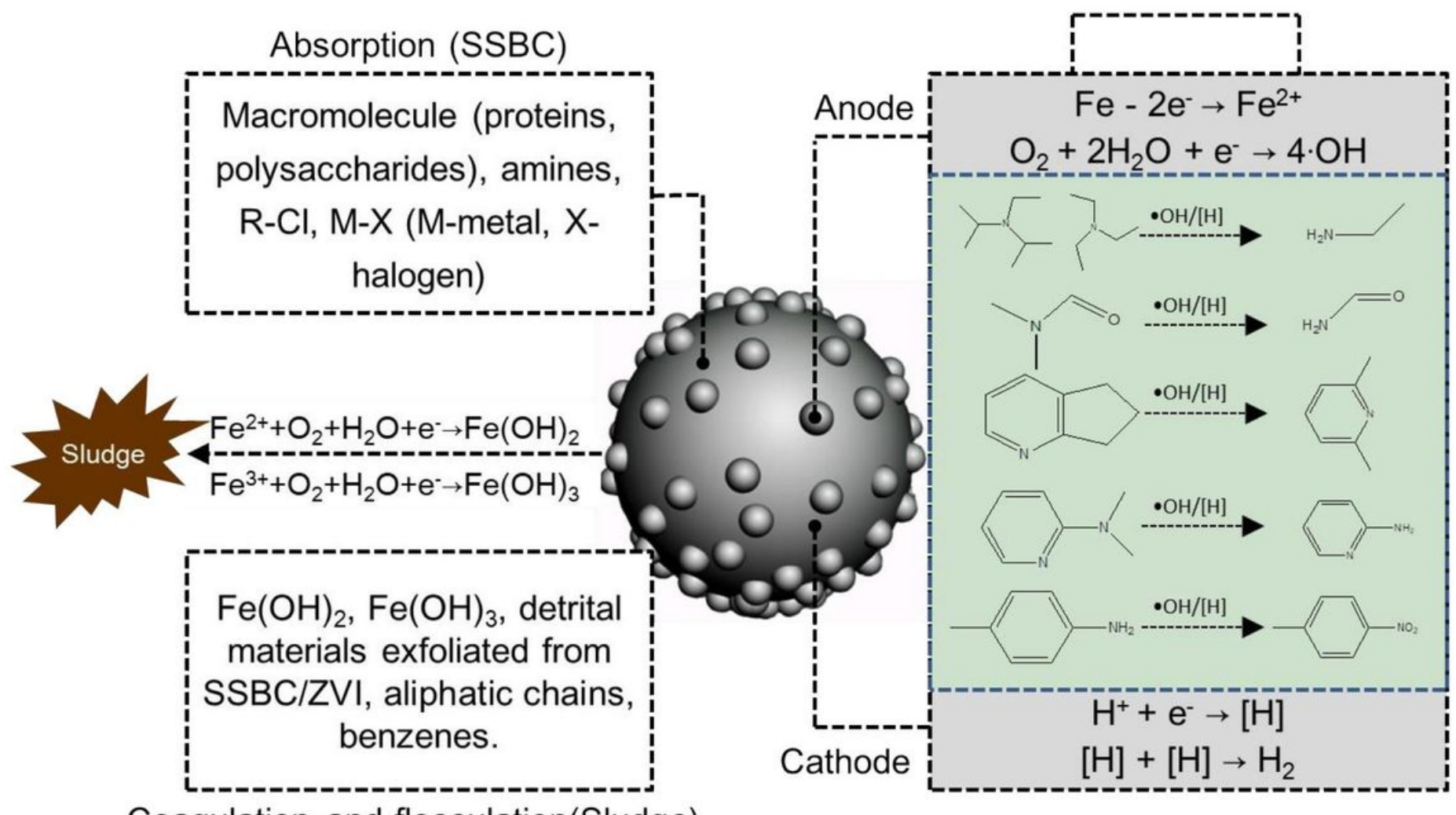

Coagulation and flocculation(Sludge)

Figure 4

Proposed mechanism of CSPW treatment by SSBC/ZVI composite filler 


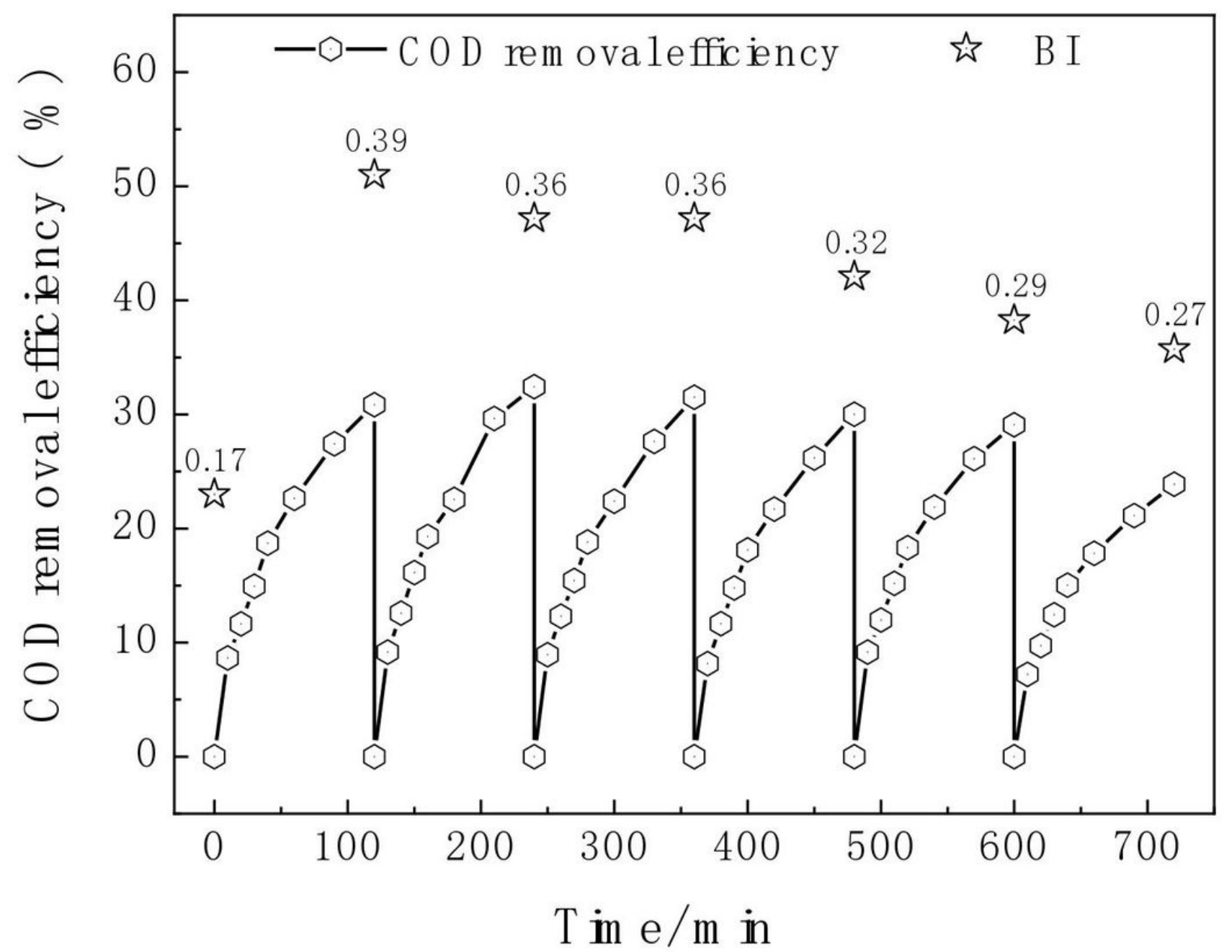

Figure 5

The reusability of SSBC/ZVI composite filler for COD removal at initial pH 3 and filler dosage of $100 \mathrm{~g} / \mathrm{L}$

\section{Supplementary Files}

This is a list of supplementary files associated with this preprint. Click to download.

- Graphicalabstract.docx 